\title{
Author Correction: Particle physics at accelerators in the United States and Asia
}

Pushpalatha C. Bhat $\mathbb{D}$ and Geoffrey N. Taylor

Correction to: Nature Physics https://doi.org/10.1038/s41567-020-0863-3, published online 6 April 2020.

In the version of this Perspective originally published, in the sentence beginning "The Japan Proton Accelerator Research Complex (J-Parc) with a $50 \mathrm{GeV}$ synchroton...”, ' $50 \mathrm{GeV}$ ' should have been ' $30 \mathrm{GeV}$ '. Also, in ref. 39, the first author name was incorrectly given as 'Delahye'; it should have been 'Delahaye'. The online versions of the Perspective have been amended.

Published online: 21 April 2020

https://doi.org/10.1038/s41567-020-0911-Z

This is a U.S. government work and not under copyright protection in the U.S.; foreign copyright protection may apply 2020

\section{Author Correction: Enhanced energy coupling for indirect-drive fast-ignition fusion targets}

F. Zhang (D), H. B. Cai (D), W. M. Zhou, Z. S. Dai, L. Q. Shan, H. Xu, J. B. Chen, F. J. Ge, Q. Tang, W. S. Zhang, L. Wei, D. X. Liu, J. F. Gu, H. B. Du, B. Bi, S. Z. Wu, J. Li, F. Lu, H. Zhang, B. Zhang, M. Q. He, M. H. Yu, Z. H. Yang, W. W. Wang, H. S. Zhang, B. Cui, L. Yang, J. F. Wu, W. Qi, L. H. Cao, Z. Li, H. J. Liu, Y. M. Yang, G. L. Ren, C. Tian, Z. Q. Yuan, W. D. Zheng, L. F. Cao, C. T. Zhou, S. Y. Zou, Y. Q. GuD, K. Du, Y. K. Ding, B. H. Zhang, S. P. Zhu D, W. Y. Zhang and X. T. He

Correction to: Nature Physics https://doi.org/10.1038/s41567-020-0878-9, published online 20 April 2020.

In the version of this Article originally published online, two affiliations were incorrect. In affiliation 1, the city was given as 'Beijing', but should have been 'Mianyang'; in affiliation 4, the institution was given as 'Department of Physics', but should have been 'College of Computing Science'. All versions of the Article have been amended.

Published online: 6 May 2020

https://doi.org/10.1038/s41567-020-0926-5

(c) The Author(s), under exclusive licence to Springer Nature Limited 2020 